JEL M 380

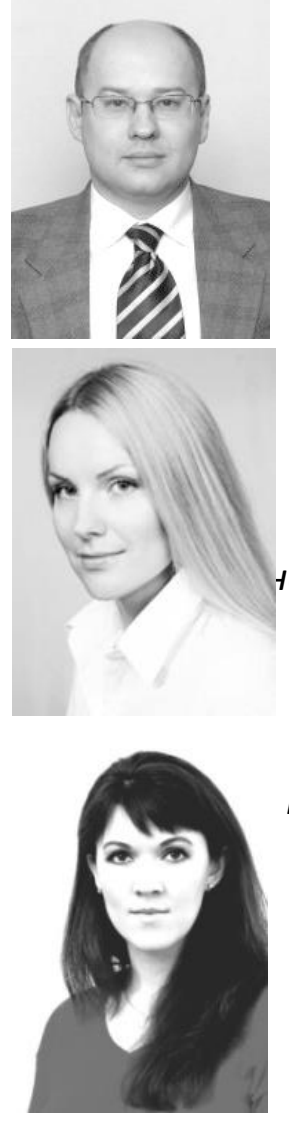

\author{
Dr hab. Dmytro Shyian ${ }^{1)}$ \\ Dr Natalia Ulyanchenko ${ }^{2)}$ \\ Dr Elena Kovalyova ${ }^{3)}$
}

${ }^{1)}$ Кафедра экономики предприятия и менеджмента, Харьковский национальный экономический университет имени Семена Кузнеца (2. Харьков, Украина) dm_shiyan@ukr.net

${ }^{2)}$ Каредра менеджмента и налогообложения, Национальный технический университет "Харьковский политехнический институт» (2. Харьков, Украина) natali_ulyan@mail.ru

${ }^{3)}$ Каредра бухгалтерского учета и аудита, Харьковский национальный аграрный университет им. В.В. Докучаева (2. Харьков, Украина) alenkov8@yandex.ru

\title{
WAGES AS AN INDICATOR OF ECONOMIC DEVELOPMENT OF THE COUNTRY
}

\section{POZIOM PŁAC JAKO WSKAŹNIK ROZWOJU GOSPODARCZEGO KRAJU}

\section{УРОВЕНЬ ЗАРАБОТНОЙ ПЛАТЫ КАК ПОКАЗАТЕЛЬ ЭКОНОМИЧЕСКОГО РАЗВИТИЯ СТРАНЫ}

\begin{abstract}
s
The dynamics of the minimum wage and subsistence level in Ukraine. The analysis of the level of the minimum wage, social guarantees; the procedure of its formation in Ukraine; conclusions on a low level of social standards: a living wage and the minimum wage. The dynamics of growth rates relative to average wage. Also the analysis of wage levels in some regions of the country during 2013-2015.

Keywords: wages, minimum wage, living wage, nominal wages, real wages Keywords: wages, minimum wage, living wage, nominal wages, real wages.

\section{Streszczenie}

Badana jest dynamika płacy minimalnej i płacy na Ukrainie. Analiza poziomu płacy minimalnej, jak spotecznej gwarancji; rozpatrzona procedura jej tworzenia na Ukrainie
\end{abstract}

Dr hab. D. Shyian, Dr N. Ulyanchenko, Dr E. Kovalyova 
wykonane sq wnioski o niskim poziomie standardów socjalnych: minimum socjalnego oraz płacy minimalnej. Badana jest dynamika wzrostu cen $w$ stosunku do poziomu średniej płacy. Również przeprowadzona analiza poziomu wynagrodzeń poszczególnych regionów kraju za lata 2013-2015.

Slowa kluczowe: wynagrodzenie, placa minimalna, minimum egzystencji, moc płace, ptace realne.

\section{Аннотация}

Исследована динамика минимальной заработной платы и прожсточного минимума в Украине. Проведен анализ уровня минимальной заработной платы, как соииальной гарантии; рассмотрена прочедура ее формирования в Украине; сделаны выводы о существенно заниженном уровне прожиточного минимума, а соответственно, и минимальной зарплаты. Исследована динамика роста иень относительно уровня средней заработной платы. Также осуществлен анализ уровня заработной платы отдельных регионов страны за 2013-2015 г2.

Ключевые слова: заработная плата, минимальная заработная плата, прожиточный минимум, номинальная заработная плата, реальная заработная пла$m a$.

Введение. На сегодняшний день острейшей социальной проблемой в Украине есть большая разница между высокой стоимостью жизни и низкой ценой труда. Оплата труда украинцев находится на одном из самых низких уровней среди других европейских стран. Поэтому данная тема исследования является актуальной, поскольку обусловлена необходимостью приближения уровня производительности труда, заработной платы и доходов наемных работников к уровню развитых стран. Это возможно осуществить путем создания соответствующих условий для высокопроизводительной трудовой деятельности между работодателями и государством.

Исследованию проблем регулирования заработной платы, установления государственных социальных стандартов занимаются такие известные ученые, как Василенко В., Гордеюк А., Гнибіденко И., Диесперов В., Куликов Г., Либанова Е., Иванечко Ю., Радчук А., Цымбалюк С. и много других. Их научные достижения являются ценными для исследования данной проблемы в современных экономических условиях развития социальноориентированной экономики страны.

Однако, признавая несомненные достижения вышеуказанных ученых, считаем необходимым более подробно исследовать уровень заработной платы и ее региональную дифференциацию в Украине.

Основной текст. Экономическое и социальное содержание заработной платы может быть определено через ее функции (воспроизводственную, мотивационную, регулирующую, социальную), виды (номинальную, реальную, минимальную), а также исходя из места и роли формирования заработной платы в укреплении факторов конкурентоспособности национальной экономики, а значит - в обеспечении экономического роста и общественного благосостояния. Для характеристики уровня оплаты труда используются понятия номинальной (начисленной), реальной (которая определяет покупательную способность) и минимальной заработной платы (которая связана с понятием прожиточного минимума или стоимости жизни) [Аналитический доклад, 2010]. Минимальная заработ-

\section{National Technical University «Kharkiv Polytechnic Institute», Kharkiv National Agrarian University named after V.V. Dokuchayev, Simon Kuznets Kharkiv National University of Economics (Kharkiv, Ukraine)




\section{International Journal of New Economics and Social Sciences № 2 (4) 2016}

ная плата - это законодательно установленный размер заработной платы за простой, неквалифицированный труд, ниже которого не может осуществляться оплата за выполненую работником месячную, а также почасовую норму труда. Минимальная заработная плата является государственной социальной гарантией, обязательной на всей территории Украины для предприятий, учреждений, организаций всех форм собственности и хозяйствования и физических лиц, использующих труд наемных работников.

Основная цель минимальной заработной платы - это защита работников с наименьшим уровнем доходов. Все работники, которые работают в течение установленного рабочего времени и выполняющих определенные нормы труда, имеют право на ежемесячное вознаграждение, которое не может быть меньшей за минимальную заработную плату. Если работник работает неполный месяц, сумма гарантированного вознаграждения определяется пропорционально до отработанного времени в этот период. К минимальной заработной платы не включаются доплаты, надбавки, поощрительные и компенсационные выплаты. Минимальная заработная плата устанавливается и пересматривается в соответствии со статьями 9 и 10 Закона Украины «Об оплате труда» [2].

Для сохранения покупательной способности денежных доходов населения проводится индексация заработной платы. Индексация - это установленный государством механизм увеличения денежных доходов граждан в связи с ростом потребительских цен. Источником выплат, связанных с индексацией заработной платы, являются собственные средства предприятий.

Обычно минимальную заработную плату устанавливают таким образом, чтобы она не была меньше, чем прожиточный минимум. Как правило, в развитых странах размер минимальной заработной платы является выше, чем прожиточный минимум, а налогообложение минимальной зарплаты (как и низких доходов в целом), осуществляется по льготным ставкам. Тем самым обеспечивается минимальной заработной платой как воспроизводственной, так и стимулирующей функций.

Более того, во многих странах устанавливаются низкие уровни минимальной заработной платы для молодежи - с тем, чтобы облегчить ее выход на рынок труда (более низкие затраты для работодателя), а с другой стороны - мотивировать к занятости [Аналитический доклад, 2010].

Основным нормативным документом, определяющим социально-экономические показатели в Украине является Закон Украины «О Государственном бюджете Украины» (на соответственный год). Для оценки среднего уровня оплаты труда в отрасли (секторе, экономике в целом или на определенной территории или отдельном предприятии) используется также понятие средней заработной платы.

В Украине в 2010 г. и 2012 г. минимальная зарплата сравнялась с прожиточным минимумом, который является крайне заниженным (табл. 1). Поэтому минимальная зарплата не выполняет стимулирующей функции, а является фактором безработицы и внешней трудовой миграции. Что касается воспроизводительной функции, то минимальная зарплата способна обеспечивать работнику фактически уровень физиологического выживания.

По соотношению минимальной и средней заработной платы можно судить о плотности шкалы трудовых доходов - чем больше доля минимальной зарплаты в средней зарплате, тем меньше дифференциация зарплат в стране, следовательно, поляризация доходов от труда.

В Украине, например, в 2015 г. это соотношение составило 29,0 \%, что вполне соответствует европейскому уровню - если не учитывать абсолютных величин минимальной и средней зарплат. Если же учесть, что минимальная зарплата в Украине равна заниженному прожиточному минимуму, то это соотношение свидетельствует о низкий уровень оплаты труда и, соответственно, средней зарплаты в Украине, и довольно несправедливым распределением дохода между трудом и капиталом. 
Такой уровень минимальной заработной платы и прожиточного минимума не дает возможности компенсировать тот рост цен, что имеет место на этот период.

Реальная (получаемая) зарплата - это реальная покупательная способность денежной суммы, полученной работником за выполненную работу. Она определяется как разница между номинальной зарплатой и совокупной суммой взысканий (налогов, отчислений в социальные фонды и других взысканий, которые налагаются на зарплату), проиндексирована согласно коэффициента инфляции. Поэтому реальная зарплата может значительно отличаться от номинальной в зависимости от совокупной суммы взысканий и уровня инфляции, который в контексте социально-трудовых отношений исчисляется как Индекс стоимости жизни. Совокупная сумма взысканий с номинальной зарплаты в процентном выражении может быть очень высокой, но для того, чтобы реальная зарплата не потеряла способности выполнять перечисленные выше функции, значимыми являются три условия:

- умеренность роста цен, то есть уровня инфляции; принципиально важным является то, что в этом случае речь идет прежде всего о потребительские цены - уровень инфляции в вычислениях динамики реальной заработной платы рассчитывается как Индекс стоимости жизни;

- достаточность остатка после взысканий и «компенсации» роста упомянутого Индекса для удовлетворения потребностей работника и его семьи на общественно приемлемом уровне (фактически - на уровне средних стандартов жизни для конкретного общества);

- эффективное и прозрачное использование средств общественных фондов (включая с государственным бюджетом), которые состоят в т.ч. из упомянутых взысканий из зарплаты, а также - обеспечения равного доступа всех граждан в качественные публичные услуги [Аналитический доклад, 2010].

\section{Таблица 1. Динамика прожиточного минимума, минимальной и сред- немесячной заработной платы в Украине, 2010-2015 гг.}

\begin{tabular}{|c|c|c|c|c|}
\hline Год & $\begin{array}{c}\text { Минимальная } \\
\text { заработная } \\
\text { плата*, грн }\end{array}$ & $\begin{array}{c}\text { Прожиточный } \\
\text { минимум*, } \\
\text { грн }\end{array}$ & $\begin{array}{c}\text { Средний уровень заработной } \\
\text { платы в расчете на 1 средне- } \\
\text { штатного работника, грн }\end{array}$ & $\begin{array}{c}\text { Соотношение мини- } \\
\text { мальной и средней } \\
\text { заработной платы, \% }\end{array}$ \\
\hline 2010 & 869 & 869 & 2250 & 38,6 \\
\hline 2011 & 941 & 894 & 2648 & 35,5 \\
\hline 2012 & 1073 & 1073 & 3041 & 35,3 \\
\hline 2013 & 1147 & 1108 & 3282 & 35,9 \\
\hline 2014 & 1218 & 1176 & 3480 & 29,0 \\
\hline 2015 & 1218 & 1176 & 4195 & \\
\hline
\end{tabular}

* - по состоянию на 1 января года

Источник: Государственная Служба Статистики, http://www.ukrstat.gov.ua, доступ от 01.08.2016 г.

Важным признаком надлежащей системы формирования заработной платы является то, что она способствует увеличению реальной заработной платы, тогда как рост номинальной зарплаты является относительно незначительным. Обычно сразу оговаривается, что для устойчивого роста реальной зарплаты необходимо повышение производительности труда, но одновременно подчеркивается и то, что рост реальной зарплаты является стимулом для работника к повышению производительности. Анализ

\section{National Technical University «Kharkiv Polytechnic Institute», Kharkiv National Agrarian University named after V.V. Dokuchayev, Simon Kuznets Kharkiv National University of Economics (Kharkiv, Ukraine)


данных табл. 2 свидетельствует о опережающий темп роста номинальной заработной платы относительно реальной. Наибольшее отклонение темпов роста номинальной заработной платы от реальной наблюдается в 2015 г. В условиях кризисного состояния экономики страны, стремительного роста цен такое явление является очевидным.

\section{Таблица 2. Темпы роста номинальной и реальной заработной платы в Украине}

\begin{tabular}{|c|c|c|c|}
\hline Год & $\begin{array}{c}\text { Номинальная заработ- } \\
\text { ная плата (к предыду- } \\
\text { щему году), \% }\end{array}$ & $\begin{array}{c}\text { Реальная заработная плата } \\
\text { (к предыдущему году), \% }\end{array}$ & $\begin{array}{c}\text { Отклонение реальной от номи- } \\
\text { нальной заработной платы }(+/- \\
\text { п.п.) }\end{array}$ \\
\hline 2010 & 117,6 & 110,2 & $-7,4$ \\
\hline 2011 & 117,7 & 108,7 & $-9,0$ \\
\hline 2012 & 114,8 & 114,4 & $-0,4$ \\
\hline 2013 & 107,9 & 108,2 & $+0,3$ \\
\hline 2014 & 106,0 & 93,5 & $-12,5$ \\
\hline 2015 & 120,5 & 79,8 & $-40,7$ \\
\hline
\end{tabular}

Источник: Государственная Служба Статистики, http://www.ukrstat.gov.ua, доступ от 01.08 .2016 г.

Стоимость отечественной денежной единицы (курса гривны к доллару) существенно влияет на размер реальной заработной платы, ведь мы используем значительную долю импортных товаров. Для примера рассмотрим в табл. 3 как менялись цены и росла заработная плата в соотношении к доллару, гривны и количества продукции, которые можно приобрести на соответствующую заработную плату.

По данным табл. 3 можем сделать вывод, что средняя заработная плата за 20092015 годы. выросла, но все же цены постоянно опережают темп ее роста. Все это привело к тому, что покупательная способность украинцев снизилась даже за уровень кризисных 2008-2009 гг. Как утверждают некоторые аналитики у людей еще оставались финансовые запасы, благодаря которым они могли не слишком экономить на товарах первой необходимости [Интернетресурс, 2015]. Но теперь украинцам приходится ограничивать себя в потреблении дорогих товаров, отдавать предпочтения базовым продуктам питания и всячески экономить на своих потребностях. Что касается прогноза тех же аналитиков, то в дальнейшем покупательная способность населения не изменится, цены на продукты будут опережать рост зарплат.

Если рассматривать среднюю заработную плату в Европе по состоянию на 2015 г., то Украина занимает последнее место, по размеру заработной платы в 178 евро. На первом же месте находится Лихтенштейн, где этот показатель составляет 4896 евро, на втором - Монако - 4436 евро, третье место занимает Швейцария со средней заработной платой в 4118 евро [Интернетресурс, 2015]. Украина является развивающейся страной, поэтому для нее должна иметь место тенденция к росту реальной заработной платы. Но проблема в том, что заработная плата растет не такими большими темпами как инфляция, следовательно, можно сказать, что население Украины становится беднее. Если обратиться к рис. 1 , то можно заметить, что почти в половине областей нашего государства этот показатель находился на достаточно низком уровне.

Анализируя данные рис. 1, можно отметить, что самый высокий уровень заработной платы наблюдается в таких регионах Украины, как Киев, Донецкая, Днепропетровская, Киевская и Луганская области. 
Таблица 3. Динамика роста цены относительно уровня средней заработной платы в Украине за 2009-2015 гг.

\begin{tabular}{|c|c|c|c|c|c|c|c|}
\hline \multirow[b]{3}{*}{$\begin{array}{c}\text { Продук- } \\
\text { ты }\end{array}$} & \multicolumn{6}{|c|}{ Год } & \multirow[b]{3}{*}{$\begin{array}{c}\text { Средняя } \\
\text { заработ- } \\
\text { ная плата }\end{array}$} \\
\hline & \multicolumn{2}{|c|}{2009} & \multicolumn{2}{|c|}{2012} & \multicolumn{2}{|c|}{2015} & \\
\hline & $\begin{array}{c}\text { Цена } \\
\text { продукта, } \\
\text { за кг }\end{array}$ & $\begin{array}{c}\text { Количе- } \\
\text { ство про- } \\
\text { дукции, } \\
\text { за одну з/п, } \\
\text { кг }\end{array}$ & $\begin{array}{c}\text { Цена } \\
\text { продук- } \\
\text { та, за кг }\end{array}$ & $\begin{array}{c}\text { Количество } \\
\text { продукции, } \\
\text { за одну } 3 / п, \\
\text { кг }\end{array}$ & $\begin{array}{c}\text { Цена } \\
\text { про- } \\
\text { дукта, } \\
\text { за кг } \\
\end{array}$ & $\begin{array}{c}\text { Количество } \\
\text { продукции, } \\
\text { за одну } 3 / п, \\
\text { кг }\end{array}$ & \\
\hline Свинина & $28-30$ & 65 & $50-52$ & 60 & 69-70 & 52 & 2009 год \\
\hline Рыба & $9-12$ & 160 & $22-25$ & 130 & $40-45$ & 90 & 1909 грн, \\
\hline Молоко & $4,5-5$ & 380 & $6-7$ & 430 & $9-10$ & 364 & $\begin{array}{c}\text { или } \\
242 \$(к у р с\end{array}$ \\
\hline Сыр & $25-35$ & 55 & $55-60$ & 50 & $80-85$ & 45 & 7,9 грн/\$) \\
\hline $\begin{array}{c}\text { Сливоч- } \\
\text { ное масло } \\
\end{array}$ & $35-40$ & 50 & $55-65$ & 50 & $\begin{array}{l}85- \\
100 \\
\end{array}$ & 40 & 2012 год \\
\hline $\begin{array}{c}\text { Подсол- } \\
\text { нечное } \\
\text { масло } \\
\end{array}$ & $13-14$ & 140 & $16-17$ & 180 & $28-35$ & 100 & $\begin{array}{l}3026 \text { грн, } \\
\text { или } 369 \$ \\
\text { (курс } 8,2\end{array}$ \\
\hline Мука & 3,5 & 545 & $4,8-5$ & 600 & $12-14$ & 260 & грн $/ \$)$ \\
\hline Caxap & $3-3,5$ & 545 & $5,4-5,5$ & 540 & 10-12 & 300 & 2015 год \\
\hline Гречка & $4,8-5$ & 385 & $7-8$ & 380 & 23-24 & 300 & 3643 грн, \\
\hline $\begin{array}{c}\begin{array}{c}\text { Яйца } \\
\text { (десяток) }\end{array} \\
\end{array}$ & $5-6$ & 320 & $8-10$ & 300 & $13-15$ & 250 & $\begin{array}{c}(\text { курс } 24 \\
\text { грн } / \$ \text { ) }\end{array}$ \\
\hline
\end{tabular}

Источник: на основании Интернет-ресурса http://www.segodnya.ua

Официальные заработки киевлян почти в два раза выше средних по стране и значительно превышают зарплаты жителей подавляющего большинства регионов Украины. На украинском рынке труда столица является лидером как по размерам заработной платы, так и по количеству вакансий. Что же касается других регионов, которые мы заметили, то это в основном, регионы с развитой тяжелой промышленностью. Однако события 2014-2015 гг. могут существенно влияют на данную ситуацию. В первую очередь это касается, безусловно, Донецкой и Луганской областей. В данных регионах существенно упала средняя заработная плата и почти прекратились инвестиции. Это уже в ближайшее время может существенно уменьшить среднюю заработную плату относительно других регионов Украины. Одна из причин этого - значительное увеличение конкуренции на рынке труда, в том числе, за счет внутреннего перемещения лиц. Указанная региональная дифференциация могла бы способствовать перераспределению трудовых ресурсов в пользу промышленных регионов - которые, кстати в период экономического роста испытывали нехватку рабочих. Однако, в Украине для такого перераспределения нет соответствующей инфраструктуры (даже транспортной), свободного рынка жилья, а также отлаженной системы профессиональной подготовки и переподготовки взрослых. При таких условиях различия в уровнях номинальных доходов населения лишь укрепляются [Ю. Ульянченко, 2013] Достаточно остро обстоит вопрос уровня заработной платы в аграрном секторе. В настоящее время сельскохозяйственное производство в Украине продолжает оставаться малоэффективным сектором экономики, что в частности вызвано отсутствием

\section{National Technical University «Kharkiv Polytechnic Institute», Kharkiv National Agrarian University named after V.V. Dokuchayev, Simon Kuznets Kharkiv National University of Economics (Kharkiv, Ukraine)


действенной системы мотивации производительного труда в отрасли. Проблемами материального стимулирования в сельском хозяйстве является нерегулярность и несвоевременность выплаты заработной платы работникам, что на фоне низкого ее уровня значительно ухудшает их материальное положение и служит фактором их мотивации. Вместе с тем, задолженность по выплате заработной платы в сельском хозяйстве имеет устойчивую положительную тенденцию к сокращению. Однако эта проблема в аграрном секторе окончательно пока не решена и продолжает негативно влиять как на мотивацию работников, так и на их материальное благосостояние [Ю. Ульянченко, 2013; Д. Шиян, 2012, А. Гуторов, 2011]. Ныне возникает неоднозначная ситуация, когда динамика реальной зара- ботной платы в гривне свидетельствует хоть и о медленном, но улучшении благосостояния украинцев, тогда как реальная зарплата в долларовом эквиваленте, наоборот, говорит об ухудшении их покупательной способности. И сложно определить, какой из показателей важнее. С одной стороны, предпочтение можно отдать первому, поскольку большинство товаров и услуг мы покупаем за гривну. Однако с другой сто-роны, в структуре нашего потребления весомую долю занимает импорт. И хотя иностранные товары мы также покупаем за национальную валюту, цена на них во мно-гом определяется валютным рынком. При таком подходе большое значение имеет второй показатель [Ю. Ульянченко, 2013].

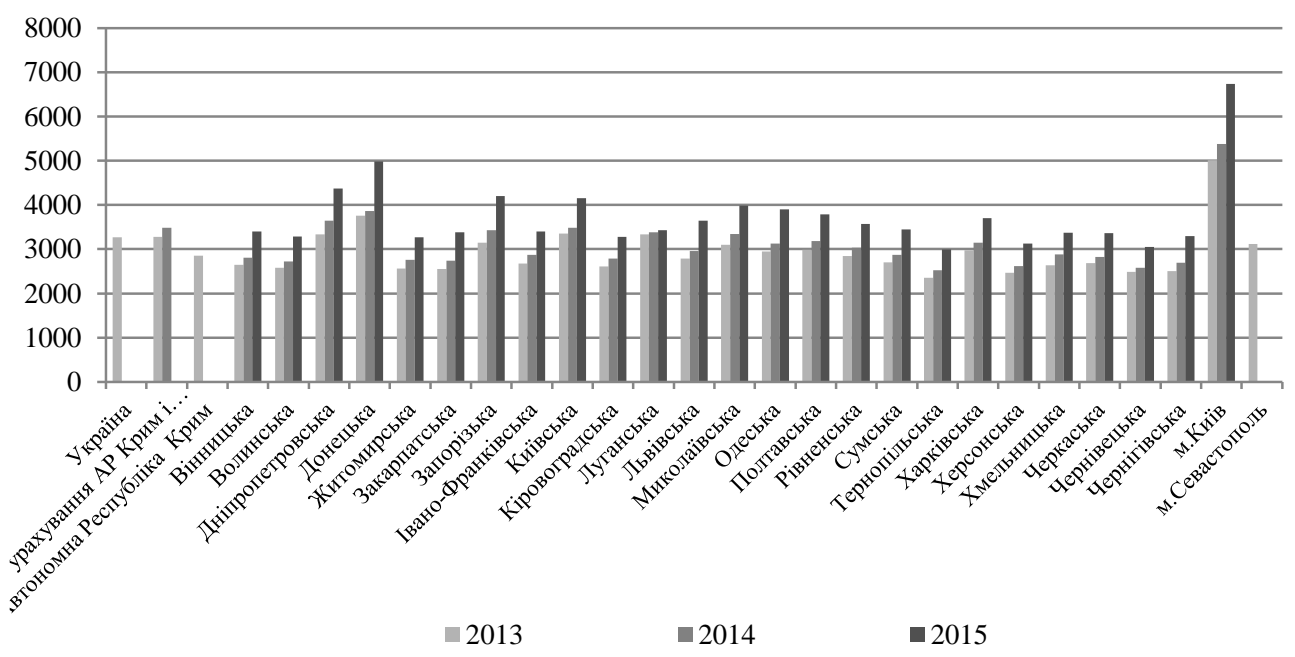

Источник: Государственная Служба Статистики, http://www.ukrstat.gov.ua, доступ от 01.08.2016 г.

Рисунок 1. Уровень заработной платы на одного работника по регионам Украины 2013-2015 гг., грн

Выводы. Таким образом, Украина на сегодняшний день находится в нестабильном экономическом и политическом состоянии. В экономике и социальной сфере проводятся серьезные изменения по поводу создания фундаментальных основ рынка.
Через низкую платежеспособность многих предприятий и бюджетного дефицита, выплаты зарплаты значительно задерживаются, происходит их натурализация, что негативно отражается на мотивации труда и стимулирует безработицу. Заработная пла- 
та практически не выполняет своих функций по воспроизводству, стимулирование перераспределения рабочей силы из-за неэффективности мер по ее реформированию, её отток зарубеж. Неприемлемым также является нынешний уровень минимальной заработной платы с учетом ее соотношения со средней заработной платой и минимальным потребительским бюджетом. Дальнейшее саморазвитие и приспособление рынка труда к современной экономической ситуации сформировали в Украине довольно противоречивые социально-трудовые от-ношения, такие как тенизиция доходов, наличие значительной скрытой безработи- цы. Регулирование рынка труда требует взаимосвязанного решения проблем в сфере макроэкономической стабилизации, структурной перестройки финансово-кредитной, бюджетной и налоговой политики, социальной защиты населения.

В Украине нет шансов добиться достойной оплаты труда без перехода к экономике, основанной на инновационных технологиях. Как показывает мировой опыт, именно инновации и инвестирование в них, а не капитал сам по себе служат главной движущей силой в повышении реальных зарплат. Много предприятий нуждаются в инвестициях для проведения модернизации, однако доступ к ним ограничен из-за коррупции в стране. Украина непривлекательна для инвестиций, которые стремятся, как правило, туда, где есть экономическая свобода и защищены права собственности.

Считаем, что государственное регулирование оплаты труда должно быть направлено, прежде всего, на создание условий для постоянного расширенного воспроизводства рабочей силы необходимого качества и стимулировать высокую производительность труда наемных работников. Государ-ство должно обеспечивать соответствующими законодательными нормами и правилами выполнения указанных требований, контролировать соблюдение экономических законов, предотвращать возникновение перекосов в дифференциации оплаты труда по категориям, группам и профессиям наемных работников, выявлять причины нежелательных тенденций и осуществлять мероприятия по их локализации и устранения.

\title{
Библиография:
}

1. Заробітна плата в Україні на шляху до економічного зростання і добробуту: аналітична доповідь. Центр Разумкова. - Національна безпека і оборона. — 2010. - №7.[Электронный ресурс], 2010 Режим доступа: http://razumkov.org.

2.Закон України «Про оплату праці» від 24.03.1995 № 108/95-ВР: [Електронний ресурс] // Режим доступу:http://zakon5.rada.gov.ua.

3. Интернет- ресурc: http://www.segodnya.ua, доступ от 01.11.2015.

4. Ульянченко Ю.О. Конкурентоспроможність аграрного сектора економіки: механізми державного регулювання: [монографія] / Ю.О. Ульянченко. - Х.: Вид-во «Асоціації докторів наук 3 державного управління», 2013. - $368 \mathrm{c}$.

5. Шиян Д.В. Ефективність витрат в сільськогосподарських підприємствах [монографія] / Д.В. Шиян., Н.В. Ульянченко - Х.: «Міськдрук», $2012-204$ с.

6. Гуторов О.І. Формування та функціонування цукробурякового підкомплексу регіону: стан і перспективи розвитку: монографія / О.І. Гуторов, О.В. Ковальова, - Харків: Міськдрук, 2011. $190 \mathrm{c}$.

\author{
National Technical University «Kharkiv Polytechnic Institute», \\ Kharkiv National Agrarian University named after V.V. \\ Dokuchayev, Simon Kuznets Kharkiv National University of \\ Economics (Kharkiv, Ukraine)

